\title{
COMMUNICATION SKILLS LEARNING DURING MEDICAL STUDIES IN POLAND: OPINIONS OF FINAL-YEAR MEDICAL STUDENTS
}

\author{
Piotr Przymuszala ${ }^{1}$, Magdalena Cerbin-Koczorowska' ${ }^{1}$, Patrycja Marciniak-Stepak ${ }^{2,3}$,

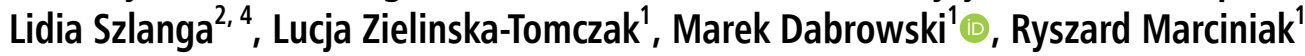 \\ ${ }^{1}$ Chair and Department of Medical Education, Poznan University of Medical Sciences, Poznan, Poland \\ ${ }^{2}$ Department of Medical Simulation, Chair of Medical Education, Poznan University of Medical Sciences, Poznan, Poland \\ ${ }^{3}$ Department of Pediatric Oncology, Hematology and Transplantology, Poznan University of Medical Sciences, Poznan, Poland \\ ${ }^{4}$ Polish Society of Medical Simulation, Poland
}

\begin{abstract}
INTRODUCTION: Despite the increasing emphasis on the medical curriculum, students' empathy and communication skills decline with time. As students' attitudes and experiences may influence the effectiveness of communication training and their future communication style, this study aimed to evaluate the opinions of last-year medical students on communication skills learning.
\end{abstract}

MATERIAL AND METHODS: Following the fully mixed concurrent equal status design methodology, we invited sixth-year medical students of our university to fill a paper questionnaire with closed and open questions on their perspectives on communication skills learning.

RESULTS: Questionnaires were completed by a representative sample of 166 students. The majority of them recognized the importance and benefits of communication training, and the need to increase its significance in the medical curriculum. They noticed that students with low communication skills lack motivation for improvement. Students also underlined the significance of the hidden curriculum, reporting a contrast between communication classes and the behavior of some physicians. Moreover, students less positively inclined towards communication training doubted its effectiveness and importance, suggesting that it should be offered for volunteers.

CONCLUSIONS: In order to meet the expectations of students with positive opinions and overcome the lack of motivation or engagement of negatively inclined students, more emphasis should be placed on communication training. Changes in communication training should include increasing its practical character and intensity, emphasizing its importance and benefits, and paying more attention to hidden curriculum aspects. Revisions to the medical school application system should be considered to underline the importance of interpersonal competencies already at the admission stage.

KEY WORDS: communication skills learning, communication training, medical students, medical curriculum, hidden curriculum 


\section{INTRODUCTION}

The patient-centered model of healthcare emphasizes the importance of patient-physician cooperation and increases the active role of patients in the therapeutic process [1]. It also stresses the significance of communication skills in the professional life of doctors [2], considering them as one of their most critical competencies [3-6]. Good communication skills of physicians improve the course and outcomes of the therapeutic process, increase patients' satisfaction, comprehension, and compliance with doctors' instructions, and decrease numbers of complaints and malpractice suits $[4,6,7]$. Positive effects of proper communication are also sensed by doctors in the form of increased comfort and satisfaction from doing their job [4]. In addition, studies show that communication skills are not innate but can be trained and systematically improved $[4,7,8]$. As a result, many medical schools introduced their teaching into curricula [8].

However, the success of communication skills learning programs may be dependent on students' attitudes towards the topic and their previous experiences, among others [9]. Furthermore, students' perception of their communication training may influence their future communication style [9]. This is consistent with Ajzen's Theory of Planned Behavior (TBP) linking behavioral intentions with attitudes, subjective norms, and perceived behavioral control [10]. Meanwhile, students' communication skills and attitudes towards them seem to decline with time [6]. For instance, Rees and Sheard [11] and Cleland et al. [12] independently showed that students in higher years presented less positive attitudes towards learning communication skills than students in lower years. Bachmann et al. [2] observed that, although last-year medical students performed better in terms of time management and differential diagnostics, deficits in their history taking and basic communication skills were noticeable. A similar decrease in their empathy levels was also observed, suggesting a close correlation between empathy, communication skills, and attitudes towards them $[2,13,14]$. The need for further studies was noticed to improve the understanding of final-year medical students' perspectives on communication deficiencies, including their experiences, challenges, role models, and educational needs [2].

Accordingly, this study aimed to examine previous experiences and opinions of last-year medical students on communication skills learning in the medical curriculum.

\section{MATERIAL AND METHODS}

\section{Researchers' characteristic}

The main researcher is a PhD student at the Department of Medical Education, who recently obtained his medical degree. During his studies, he often observed deficiencies in communication skills and differentiated attitudes towards them among other students and doctors. As a result, after graduation, he decided to examine this phenomenon more thoroughly. To avoid bias caused by the main researcher's personal experiences, the research team was broadened to include researchers with different backgrounds. The second researcher is a pharmacist experienced in qualitative research methods. The third researcher is a physician with a specialty in pediatric hemato-oncology and experience in teaching communication skills with simulated patients. The fourth researcher is a nurse and the sixth researcher is a medical rescuer - they both are experienced simulation instructors. The fifth researcher is a pharmacist with an additional Bachelor's degree in Public Health, serving as an asset in the data interpretation process. The senior researcher is a physician with a specialty in surgery and extensive clinical experience.

\section{Research approach}

The mixed-methods research utilizes both qualitative and quantitative approaches during the data collection and analysis, integrating findings and drawing interferences to increase the depth of understanding of a given phenomenon $[15,16]$. It should be distinguished from multi-method research, which collects multiple types of qualitative or quantitative data [17]. Moreover, mixed-methods research should not only aim to collect both qualitative and quantitative data but rather integrate both approaches and data sets across the entire study [18]. In this study, we chose the fully mixed concurrent equal status design according to the classification proposed by Leech and Onwuegbuzie [19]. We chose this method to collect data from a bigger, representative group of students and therefore increase the generalizability of our results in comparison with a purely qualitative approach using interviews, for instance. In this way, we tried to avoid a situation when only students with strong positive or negative opinions would agree to participate in the study. As we wanted to make this study an indication of areas that, in students' opinion, might require some changes in the 
shape of the medical curriculum at our institution, it was also crucial for us to ensure that respondents present their genuine views on the topic. We believed that an anonymous paper questionnaire seems to suit this purpose better than an interview, which could be potentially associated with a risk of students hiding their negative thoughts and experiences.

\section{Study settings}

The study was conducted on a sample of sixth-year medical students of Poznan University of Medical Sciences in the academic year 2019/2020. Students were approached on the first day of the Advanced Medical Simulation clerkship in the Center for Medical Simulation and asked to fill a paper questionnaire on their previous experiences and opinions on communication skills learning. The survey consisted of closed questions with a vignette of answers followed by open questions asking students to explain their choice of answer to that question. It allowed us to get a deeper understanding and context of their responses regarding the topic of the study. The outline of questions asked in the study was presented in the tables in the Results section. Exemplary students' responses to open questions were accompanied in the Results section with a brief demographic characteristic of respondents (for example, F/24 next to a quote indicates that this particular response was added by a female student who is 24 years old). The questionnaire was pre-tested on 10 respondents participating in the first edition of the clerkship to ensure its clarity.

Medical studies in Poland last for six years and are regulated by an appropriate Ordinance of the Ministry of Science and Higher Education. Members of the study group started their studies in 2014, when the Ordinance of May 9, 2012, was in force [20]. Learning outcomes dedicated to communication skills imposed by it are presented in Table 1. Respondents' medical curriculum was divided into two years of pre-clinical training focused on basic sciences, followed by four years of clinical education, during which students rotated between different clerkships (Tab. 2). Most of the formal communication training was conducted during the first two years of their studies, for instance, during professionalism or psychology classes. From the third year onwards, their curriculum assumed learning communication mostly with real patients during clinical rounds and medical simulation clerkships. Additionally, willing students could choose communication classes among their electives.

There were 271 sixth-year medical students in the academic year 2019/2020. Initially, we planned to invite all of them to participate in the study. How-

Table 1. Learning outcomes dedicated to communication skills in the Ordinance of may 9, 2012

\begin{tabular}{|l|l|}
\hline \multicolumn{3}{|l|}{ In terms of knowledge, a graduate: } \\
\hline D.W4. & $\begin{array}{l}\text { "Understands the significance of verbal and non-verbal communication in the communication process with patients } \\
\text { and the notion of trust in the interaction with the patient" }\end{array}$ \\
\hline D.W12. & "Knows the rules of motivating patients to pro-health behaviors and informing about adverse prognosis" \\
\hline \multicolumn{2}{|l|}{ In terms of skills, a graduate: } \\
\hline D.U1. & $\begin{array}{l}\text { "Acknowledges in the therapeutic process subjective needs and expectations of the patient arising from socio-cultural } \\
\text { factors" }\end{array}$ \\
\hline D.U4 & "Builds the atmosphere of trust during the whole therapeutic process" \\
\hline D.U5. & $\begin{array}{l}\text { "Conducts a conversation with an adult patient, a child and the family using active-listening and showing empathy } \\
\text { techniques and talks with a patient on their life situation" }\end{array}$ \\
\hline D.U6. & $\begin{array}{l}\text { "Informs the patient about the aim, course and eventual risk of proposed diagnostic and therapeutic actions and } \\
\text { obtains their informed consent" }\end{array}$ \\
\hline D.U7. & "Gives the patient and their family about adverse prognosis" \\
\hline D.U8. & "Gives advice on compliance with therapeutic orders and pro-health lifestyle" \\
\hline D.U9. & "Identifies risk factors of violence, recognizes violence and reacts adequately" \\
\hline D.U10. & "Utilizes to the basic degree motivating and supporting psychological interventions" \\
\hline E.U1. & "Takes a history from an adult patient" \\
\hline E.U2. & "Takes a history from a child and their family" \\
\hline
\end{tabular}

Developed on the basis of: Ordinance of the Minister of Science and Higher Education of May 9, 2012 on the standards of education for faculties: medical, dentistry, pharmacy, nursing and obstetrics. [Rozporządzenie Ministra Nauki i Szkolnictwa Wyższego z dnia 9 maja 2012 r. w sprawie standardów kształcenia dla kierunków studiów: lekarskiego, lekarsko-dentystycznego, farmacji, pielęgniarstwa i położnictwa.] Retrived from: http://prawo.sejm.gov.pl/isap.nsf/DocDetails.xsp?id=WDU20120000631. 
Table 2. An outline of the curriculum of students participating in the study

$$
\text { First year }
$$

Anatomy (200 h); Histology and embryology (110 h); Physiology (75 h); Biochemistry (65 h); English (60 h); Biophysics (55 h); Molecular biology (30 h); Chemistry (30 h); First aid with elements of nursing (30 h); Cytophysiology (20 h); Biostatistics with elements of informatics (20 h); History of medicine (15 h); Hygiene (15 h); Electives (4x15 h); Summer internship (120 h)

\section{Second year}

Physiology (80 h); Biochemistry (70 h); Pathophysiology (70 h); Laboratory diagnostics (65 h); English (60 h); Microbiology (60 h); Immunology (60 h); Cardiopulmonary resuscitation (30 h); Medical ethics with elements of deontology (30 h); Medical psychology (30 h); Parasitology (25 h); Sociology of medicine (25 h); Epidemiology (20 h); Elements of professionalism (20 h); Biostatistics with elements of informatics (20 h); Electives (4x15 h); Summer internship (120 h)

\section{Third year}

Pathology (170 h); Pharmacology and toxicology (140 h); Pediatrics (75 h); Genetics (70 h); Radiology (70 h); Dermatology (65 h); Internal diseases (60 h); Surgery (60 h); Emergency medicine (35 h); Oncology (30 h); Electives (4x15 h); Summer internship (120 h)

\section{Fourth year}

Internal diseases (120 h); Surgery (120 h); Pediatrics (95 h); Gynecology and obstetrics (80 h); Orthopedic surgery and traumatology (60 h); Infectious diseases (60 h); Psychiatry (60 h); Oncology (45); Palliative medicine (30); Geriatrics (30 h); Emergency medicine (30 h); Neonatology (30 h); Tropical and parasitic diseases (30 h); Medical simulation (20 h); Transplantology (20 h); Rehabilitation (20 h); Public health (20 h); Nuclear medicine (15 h); Electives (4x15 h); Summer internship (120 h)

\section{Fifth year}

Internal diseases (120 h); Surgery (100 h); Neurology (95 h); Gynecology and obstetrics (90 h); Pediatrics (80 h); Family medicine $(60 \mathrm{~h}) ;$ Anesthesiology (60 h); Otolaryngology (60 h); Ophthalmology (60 h); Forensic medicine and medical law (50 h); Clinical pharmacology (35 h); Audiology and phoniatrics (15 h); Electives (4x15 h); Summer internship (120 h)

\section{Sixth year}

Internal diseases (240 h); Pediatrics (120 h); Surgery (120 h); Gynecology and obstetrics (60 h); Psychiatry (60 h); Emergency medicine (60 h); Family medicine (60 h); Medical simulation (20 h); Chosen specialty (180 h)

ever, due to the COVID-19 pandemic outbreak, all stationary classes at Polish schools and universities were canceled in the middle of March 2020 by the government authorities and continued online. By that time, we already collected 166 received questionnaires, which signifies an adequate sample size [21]. As a result, we decided not to put additional pressure and burden on students in these difficult times and resigned from continuing data collection online.

\section{Data analysis}

Data obtained from the questionnaires were transcribed and subjected to subsequent analysis. Quantitative data were analyzed with the Wilcoxon signed-rank test, the Mann-Whitney $U$ test, and Fisher's exact test, as appropriate, using the Statistica Software (StatSoft) and PQStat Software. Qualitative data were encoded and analyzed with the Atlas.ti Software (ATLAS.ti 8 EDU) by two independent researchers. They individually familiarized themselves with data, identified important fragments of students' respondents, then compared their results and debated until reaching consensus. We decided to use phenomenology as a qualitative approach to obtain a thorough picture of students' opinions and experiences on the topic [22]

\section{Ethical considerations}

The study protocol was presented to the institutional review board (Bioethics Committee of Poznan University of Medical Sciences) for opinion, which decided that ethical approval was not necessary under the Polish law. Before receiving the questionnaires, students were informed about the aims and protocol of the study. They were assured that their participation was voluntary and that all data would be obtained and processed anonymously. No data enabling their identification were collected. Students were asked to sign a written consent form, which also contained the information listed above. During the study, we paid attention to meeting the Ethical Guidelines for Educational Research [23].

\section{RESULTS}

Of the 166 students who returned the questionnaires, 104 (62.65\%) were female, 60 (36.14\%) male and $2(1.20 \%)$ did not disclose their gender. The age of respondents ranged from 22 to 
34 years $($ mean $=24.8$; median $=24$; interquartile range $=24-25$ ). As indicated above, the qualitative data presented below were supplemented with the demographical characteristic of the respondent, including their gender ( $\mathrm{F}$ - female, $\mathrm{M}$ - male) and age.

As presented in Table 3, the majority of students $(n 4+5=158 ; 96.34 \%)$ considered the communication skills necessary for physicians. Still, in their opinion, they were only occasionally made aware of that during the studies. On average, students rated the communication skills of physicians as moderate but admitted that their level was diversified. Students' opinions were not influenced by their gender.

There were doctors who communicated perfectly and ones who did not have such skills. (F/24)

Unfortunately, the communication skills of most doctors were not too good. (F/24)

Students appreciated doctors who acknowledged the perspective and needs of the patient, provided clear and detailed information on their condition and treatment options, and were showing them empathy and respect. On the other hand, students were dissatisfied with doctors who were clearly in a hurry, spent little time talking to the patients, or interrupted them. They were also displeased when doctors asked predominantly closed questions, did not verify whether patients understood the information, were patronizing and did not focus on the patient's emotions. Additionally, difficulties of some physicians with giving bad news were noted. Students also pointed out that some doctors might not perceive communication with patients as one of their duties or just not care about it. They also noticed that physicians might be tired, overworked, burnt-out, and lack time to improve their communication.

Communication skills of physicians encountered as students were rated statistically higher than those of physicians contacted as patients or the family of the patient $(p=0.002)$. Some students pointed out that the communication skills of academic teachers may be improved by their teaching experience and awareness of the hidden curriculum. However, it was also suggested that a narrow profile of patients at clinical hospitals might work at their disadvantage.

\begin{tabular}{|c|c|c|c|c|c|c|c|c|c|c|c|}
\hline Question asked & Group & $\mathrm{n} 1$ & $\mathrm{n} 2$ & n3 & $\mathrm{n} 4$ & $\mathrm{n} 5$ & Mean (SD) & $\mathrm{M}$ & $\mathrm{Q}_{1}$ & $\mathrm{Q}_{3}$ & $\mathrm{p}$-value \\
\hline \multirow{3}{*}{$\begin{array}{l}\text { Are communication skills } \\
\text { necessary in the physician's } \\
\text { profession? } \\
\text { (1: definitely no, } \\
\text { 5: definitely yes) }\end{array}$} & $\begin{array}{l}\text { Total } \\
\mathrm{n}=164\end{array}$ & 1 & 3 & 2 & 42 & 116 & $4.64(0.66)$ & 5 & 4 & 5 & \\
\hline & $\begin{array}{l}\text { Females } \\
n=103\end{array}$ & 0 & 1 & 1 & 25 & 76 & $4.71(0.53)$ & 5 & 4 & 5 & \multirow[t]{2}{*}{0.238} \\
\hline & $\begin{array}{l}\text { Males } \\
n=59\end{array}$ & 1 & 2 & 1 & 16 & 39 & $4.53(0.83)$ & 5 & 4 & 5 & \\
\hline \multirow{3}{*}{$\begin{array}{l}\text { How often during your studies } \\
\text { were you made aware of the } \\
\text { role of communication in the } \\
\text { physician's profession? } \\
\text { (1: not at all, } \\
\text { 5: very often) }\end{array}$} & $\begin{array}{l}\text { Total } \\
\mathrm{n}=164\end{array}$ & 6 & 43 & 47 & 56 & 12 & $3.15(1.01)$ & 3 & 2 & 4 & \\
\hline & $\begin{array}{l}\text { Females } \\
\mathrm{n}=104\end{array}$ & 5 & 23 & 25 & 45 & 6 & $3.23(1.01)$ & 3 & 2 & 4 & \multirow[t]{2}{*}{0.086} \\
\hline & $\begin{array}{l}\text { Males } \\
\mathrm{n}=58\end{array}$ & 1 & 20 & 21 & 10 & 6 & $3.00(1.00)$ & 3 & 2 & 4 & \\
\hline \multirow{3}{*}{$\begin{array}{l}\text { Rate communication skills of } \\
\text { physicians you encountered } \\
\text { as a patient/patient's family } \\
\text { member } \\
\text { (1: very poor, 5: very good) }\end{array}$} & $\begin{array}{l}\text { Total } \\
\mathrm{n}=164\end{array}$ & 11 & 27 & 79 & 39 & 8 & $3.04(0.93)$ & 3 & 3 & 4 & \\
\hline & $\begin{array}{l}\text { Females } \\
\mathrm{n}=102\end{array}$ & 8 & 18 & 46 & 28 & 2 & $2.98(0.92)$ & 3 & 2.25 & 4 & \multirow[t]{2}{*}{0.440} \\
\hline & $\begin{array}{l}\text { Males } \\
n=60\end{array}$ & 3 & 8 & 32 & 11 & 6 & $3.15(0.95)$ & 3 & 3 & 4 & \\
\hline \multirow{3}{*}{$\begin{array}{l}\text { Rate communication skills of } \\
\text { physicians you encountered as } \\
\text { a student } \\
\text { (1: very poor, 5: very good) }\end{array}$} & $\begin{array}{l}\text { Total } \\
n=163\end{array}$ & 5 & 15 & 91 & 44 & 8 & $3.21(0.80)$ & 3 & 3 & 4 & \\
\hline & $\begin{array}{l}\text { Females } \\
n=102\end{array}$ & 3 & 6 & 62 & 27 & 4 & $3.23(0.74)$ & 3 & 3 & 4 & \multirow[t]{2}{*}{0.726} \\
\hline & $\begin{array}{l}\text { Males } \\
n=60\end{array}$ & 2 & 9 & 29 & 16 & 4 & $3.18(0.88)$ & 3 & 3 & 4 & \\
\hline
\end{tabular}

nX: the number of respondents who chose particular answers; M: median; $Q_{1}$ : lower quartile; ${ }^{\text {hh }} \mathrm{Q}_{3}$ : upper quartile, $p$-values analyze gender differences in students' answers 
Academic teachers, due to the character of their work, have better-developed communication skills than the majority of 'common' doctors. (M/25)

Often good communication with patients because they want to give us a good example. (F/26)

Clinicians are much less empathic; it rather resembles mass treatment than paying attention to the patient. $(\mathrm{M} / 24)$

Communication with patients constituted an easy task for $49.09 \%$ of students and a difficult task for $15.76 \%$ of them. The majority of students believed that learning communication skills should be an obligatory part of the medical curriculum $(135 ; 81.33 \%)$ and that the amount of time dedicated to it during their studies was insufficient (104; $63.03 \%)$. On the contrary, 53 (32.12\%) students replied that the amount of time dedicated to learning communication skills was adequate, and 8 (4.85\%) students thought that too much time was spent on it. The detailed results are presented in Table 4. Students' responses did not differ statistically in terms of their gender.

Students who responded that communication training should be obligatory for medical students noticed it would allow for better preparation for conversations with actual patients and bring many profits for them and their future patients. As a result, learning communication skills was seen as an investment in the future. Respondents argued that good communication skills are essential for physicians as they influence patients' perception of care quality and facilitate patient-physician cooperation. Good communication with patients was also seen as helpful in understanding the patient's perspective, showing them respect, and realizing their right to information about their condition and treatment options. Its importance was emphasized, especially in the context of difficult conversations with patients. However, respondents noticed that learning communication skills is highly dependent on the willingness, motivation, and engagement of students.

There is a gap between talking with patients at clinical classes and talking with patients on our own. Communication classes allow us to fill it. (M/24)

It [learning communication skills] allows starting to work as a physician more easily. (F/23)

Better preparation for the conversation with a patient, sensing what they want to know, what their expectations are. (F/24)

Good communication shows the class of a physician. (M/24)

Students noticed that some of their colleagues might have bigger deficits in communication skills and interpersonal competencies, especially that they are not taken into account when applying to medical schools in Poland.

Many people beginning medical studies have poorly developed emotional intelligence, and due to their young age, they do not have experience in communication with people from the entire cross-section of society. (F/24)

\begin{tabular}{|c|c|c|c|c|c|}
\hline \multirow{2}{*}{ Question asked } & \multirow{2}{*}{ Answers } & \multicolumn{3}{|c|}{$\mathrm{n}(\%)$} & \multirow{2}{*}{ p-value* } \\
\hline & & Total & Females & Males & \\
\hline \multirow[t]{3}{*}{ For me, communicating with patients is ... } & Easy & $81(49.09)$ & $50(48.08)$ & $30(50.85)$ & \multirow[t]{3}{*}{0.951} \\
\hline & Difficult & $26(15.76)$ & $18(17.31)$ & $8(13.56)$ & \\
\hline & Hard to say & $58(35.15)$ & $36(34.62)$ & $21(35.59)$ & \\
\hline \multirow{3}{*}{$\begin{array}{l}\text { Should communication skills learning } \\
\text { be an obligatory part of the medical } \\
\text { curriculum? }\end{array}$} & Yes & $135(81.33)$ & $84(80.77)$ & $50(83.33)$ & \multirow[t]{3}{*}{0.428} \\
\hline & No & $9(5.42)$ & $7(6.73)$ & $2(3.33)$ & \\
\hline & Hard to say & $22(13.25)$ & $13(12.50)$ & $8(13.33)$ & \\
\hline \multirow{3}{*}{$\begin{array}{l}\text { The amount of time dedicated to learning } \\
\text { communication skills in the curriculum } \\
\text { is... }\end{array}$} & Too big & $8(4.85)$ & $7(6.73)$ & $1(1.69)$ & \multirow[t]{3}{*}{0.414} \\
\hline & Appropriate & $53(32.12)$ & $35(33.65)$ & $17(28.81)$ & \\
\hline & Insufficient & $104(63.03)$ & $62(59.62)$ & $41(69.49)$ & \\
\hline \multirow{3}{*}{$\begin{array}{l}\text { Could some changes be made to improve } \\
\text { the communication skills of future } \\
\text { doctors? }\end{array}$} & Yes & $92(55.76)$ & $58(56.31)$ & $33(55.00)$ & \multirow[t]{3}{*}{0.242} \\
\hline & No & $17(10.30)$ & $7(6.80)$ & $10(16.67)$ & \\
\hline & Hard to say & $56(33.94)$ & $38(36.89)$ & $17(28.33)$ & \\
\hline
\end{tabular}

${ }^{*} \mathrm{p}$-values analyze gender differences in students' answers 
It is important in the light of societal changes happening under the influence of technological development and weakening of the interpersonal relations. $(\mathrm{M} / 26)$

Because the sole admission criterion to medical schools is the result of the baccalaureate exams, there are many medical students with low social and interpersonal competencies. (M/26)

Students who opposed the idea of obligatory communication training were skeptical about its effectiveness and saw it as a waste of their time. They also emphasized the importance of individual student's engagement and motivation, suggesting that communication skills learning should be offered as electives.

If someone was not able to learn throughout the years to communicate with people appropriately, classes won't change that. (M/24)

I think it is a waste of time on such time-absorbing studies. (F/24)

If someone doesn't want to acquire communication skills, they won't gain anything from these classes. (F/24)

Students who remained undecided argued that not every physician might need communication skills. They also doubted the effectiveness of communication training or expressed indifference to the topic.

I think that it cannot be learned. (M/24)

It all depends on the person [...]. However, if someone is interested, it might be helpful. (F/24)

The majority of students declared that the amount of time dedicated to communication skills learning during their studies was insufficient, especially in comparison with basic sciences. Students noted that most of the communication training was offered as elective classes, and many topics were overlooked. As a result, they suggested increasing the intensity of communication skills learning both in the pre-clinical and clinical training. Respondents acknowledged deficits in communication skills among students, and therefore expressed a demand for more individual conversations with patients, and believed that students' communication skills should be assessed. Another theme emerging from students' comments was the significance of the hidden curriculum. They reported a contrast between what they were told at communication classes and the example given by some medical teachers.

During the classes, we talk with patients, but in groups. There is a lack of individual conversations. $(M / 25)$
Many situations from the everyday work of a physician are not discussed. (M/24)

It would be best if aspects of interculturalism were also brought up. There are only elective classes on that. (F/23)

It is never too much. Moreover, physicians giving other classes too rarely comply with the knowledge from simulation classes [on communication skills]. $(\mathrm{M} / 24)$

Students who responded that too much time was spent on communication training believed that it should be conducted in a clinical setting. They also doubted its effectiveness and regarded communication skills as less important than medical knowledge, for instance.

Students believing that the amount of time was appropriate suggested its better use, for instance, introducing more simulation methods instead of theory. They also referred to students' motivation and proposed additional elective courses for volunteers.

Even if there were more of them, some [students] still wouldn't learn it. (F/24)

Classes should only show a path of development. Students should train out of their own will. (M/24)

Some students should be motivated to communicate, because, in my group, there are people who never speak, take the history from the patient. (F/24)

For interested people, elective courses on the topic can be organized. (F/24)

Finally, nearly $56 \%$ of students indicated that some changes could be introduced to improve the communication skills of future doctors (Table 4). They proposed more compulsory communication classes and occasions to practice their skills during pre-clinical and clinical training, including simulation methods (e.g., simulated patients), peer role-plays, or psychology classes. Students also suggested paying more attention to their communication skills during other classes, more individual interactions with patients, and wished for more teacher feedback in this regard. They expressed a particular demand for elaborating on the topic of difficult conversations with patients. Respondents also mentioned workshops for teachers and broadening the curriculum to include interprofessional education and courses focused on multicultural and minority patients. Finally, apart from curricular changes, students also implied a revision of the medical school application system in Poland.

More classes with simulated patients and working in pairs, where people play given roles and situations. (M/25) 
Bringing it up during clinical classes - observation of our history-taking skills and then comments on it. (F/24)

More practical classes oriented towards conversations with patients, not necessarily in simulated conditions - one or two students and a medical teacher. (M/25)

Not only history taking, but also the possibility to observe and actively participate in difficult conversations. (F/25)

More training sessions for medical teachers so they could show the importance of communication skills by giving a good example. (F/24)

Interfaculty classes with nursing, medical rescue, midwifery students should be organized. (F/24)

A multicultural patient, LGBT+, a requirement of at least 30 minutes at every ward about the specificity of their patients. (F/23)

Not only [changes in] the curriculum, but also, e.g., psychological tests before the studies. (F/24)

Admission interviews and selecting the candidates with regards to psychological predispositions; more soft skills learning. (M/22)

\section{DISCUSSION}

The majority of students acknowledged the importance of communication skills in their future profession. However, the comparatively lower frequency with which they were made aware of that during their studies might raise concerns. Students who are less positively inclined to learn communication skills may even see it as a subliminal message that maybe the topic is not so important after all. Furthermore, it is essential for medical students, as adult learners, to know why they should learn something and how it is relevant for their future work $[24,25]$. Students moderately rated the communication skills of doctors encountered in the past, noting a requirement for improvement in some cases. Interestingly, we observed a statistically significant difference in their perception of the communication skills of physicians encountered as medical students and patients. Meanwhile, Ajzen's Theory of Planned Behavior places subjective norms among variables influencing one's behavioral intentions [10]. As a result, the attention that medical teachers, as authority figures, pay to communication skills, and the example they give to their students may be of great importance. Students' comments show the significance of the hidden curriculum and how carefully they observe their teachers. They provided many examples of qualities indicating good and bad communication role-models, mirrored by the literature [26]. The significance of positive and negative role models was also demonstrated in previous studies $[27,28]$. It was even suggested that negative examples might leave a more profound impact on students in terms of what not to do [28]. Still, it seems advisable to avoid and correct them in order to prevent their legitimization. In this aspect, medical teachers should be aware of their communication style, limitations, being a role model, and the need for constant improvement [29].

Students strongly believed that communication skills learning should be an obligatory part of the medical curriculum, and the majority of them would welcome the opportunity to have more classes on it, providing many reasons for both answers. Simultaneously, they recognized the struggles of some students with talking to patients. On the other hand, students with less positive opinions on communication training expressed skepticism about its effectiveness in terms of communication skills as something that cannot be learned. They also pointed out that communication skills might not be required in particular medical specialties and emphasized that students unwilling or unmotivated to learn communication skills would not benefit from them anyway. Similar negative attitudes of some students towards communication skills learning were noted previously $[30,31]$. Knowles also underlined the importance of internal motivation and learner-centeredness in adult education $[24,25]$.

Students proposed many changes that could be introduced to their communication training, including increasing its intensity and practical relevance. They suggested more classes with simulated patients, peer role-play, psychology classes, and more conversations with real patients in supervised conditions with subsequent feedback. Rees et al. [32] also noted positive attitudes of students towards experiential learning methods and suggested increasing their opportunities for conversations with simulated and real patients. Moreover, medical simulation presents students with the opportunity to practice their communication skills in safe conditions with respect to scenarios that would otherwise be difficult to implement in their curriculum, for instance, patients' death, aggression, or cultural differences [33]. Additionally, it not only allows learners to improve and develop their knowledge, skills, and critical thinking 
but also prepares them for handling similar situations in their future professional work [34]. Other studies showed learners' positive perception and effectiveness of communication training in a clinical setting [35-37]. The role of feedback in improving students' communication is also invaluable [38]. As demonstrated by this and other studies $[39,40]$, students expect to be observed and receive feedback on their performance. However, reports show that it either happens rarely or is performed only superficially [29].

Students mentioned broadening the curriculum to include interprofessional education and courses focused on multicultural and minority patients. Given that currently they are only being introduced into the Polish medical curriculum and, at least at our institution, are offered only as elective courses, we were positively surprised that students start to notice a requirement for them. It could signify their readiness for them as a compulsory part of the curriculum. However, verification of this would require additional studies. Finally, apart from curricular changes, students also implied a revision of the medical school application system in Poland, including admission interviews and evaluation of psychological predispositions of candidates. It should be explained that currently, according to Polish law, admission to any university is based only on the results of baccalaureate exams. In the case of medical schools, results in Biology, Chemistry, and sometimes Physics are taken into account. However, as our respondents also noticed, it may lead to people with deficits in communication and interpersonal skills getting into medical schools. Furthermore, given that currently, communication skills are not formally assessed during medical studies, their deficits may remain undetected. It seems that more emphasis should be placed on communication skills in the Polish medical curriculum, including their formative and summative assessment with equal treatment as other exams.

We acknowledge the limitations of this study. Due to circumstances beyond our control caused by the COVID-19 pandemic outbreak, we were not able to collect data from all sixth-year students as we initially planned. Still, the sample size was representative of the entire group of students. Furthermore, the number of male respondents was lower than females, but it was corresponding with the general demographic characteristic of medical students. According to the data provided by the Office for Student Affairs of Poznan University of Medical Sciences, among 271 sixth-year medical students in the academic year 2019/2020, there were 176 (64.94\%) females and 95 (35.06\%) males. Furthermore, a research bias cannot be excluded, given a strong attachment of the primary author to the topic. However, to compensate for that, researchers with different backgrounds were invited to the study. Finally, this study was conducted among students of only one medical university, and students from other institutions might present different opinions on communication skills. Further studies are needed to extend our results to a broader population.

\section{CONCLUSIONS}

Medical students observe the communication style of their teachers and pay attention to the hidden curriculum conveyed by them. They report a contrast between the behavior of some physicians and issues raised during communication classes. For the majority of students, communication skills learning should be obligatory in medical schools, and due to its many benefits, it was perceived as an investment in the future. However, students who were undecided or opposing this idea doubted its effectiveness and underlined the importance of individual students' attitudes and motivation as essential for its success. Most students believed that, for many reasons, more time should be spent on communication training in the medical curriculum. Necessary changes proposed by respondents that could be introduced into the medical curriculum included increasing the intensity and emphasis on communication training, bigger use of experiential learning methods, interprofessional education, and multicultural education. Students noted that medical teachers should pay more attention to their communication style during clinical classes and provide them with more occasions for individual conversations with patients, followed by feedback on their skills. Revisions to the medical school application system were suggested, for instance, psychological screening and admission interviews with candidates.

\section{Acknowledgments}

We wish to express our gratitude to all students who agreed to participate in the study.

\section{Conflict of interest}

The authors declare that there are no conflicts of interest. 


\section{REFERENCES}

1. Epstein RM, Street RL. The values and value of patient-centered care. Ann Fam Med. 2011; 9(2): 100-103, doi: 10.1370/afm.1239, indexed in Pubmed: 21403134.

2. Bachmann C, Roschlaub S, Harendza S, et al. Medical students' communication skills in clinical education: Results from a cohort study. Patient Educ Couns. 2017; 100(10): 1874-1881, doi: 10.1016/j. pec.2017.05.030, indexed in Pubmed: 28601262.

3. Cömert M, Zill JM, Christalle E, et al. Assessing Communication Skills of Medical Students in Objective Structured Clinical Examinations (OSCE)--A Systematic Review of Rating Scales. PLoS One. 2016; 11(3): e0152717, doi: 10.1371/journal.pone.0152717, indexed in Pubmed: 27031506.

4. Löffler-Stastka H, Seitz T, Billeth S, et al. Significance of gender in the attitude towards doctor-patient communication in medical students and physicians. Wien Klin Wochenschr. 2016; 128(17-18): 663-668, doi: 10.1007/s00508-016-1054-1, indexed in Pubmed: 27516078.

5. Baig LA, Violato C, Crutcher RA. Assessing clinical communication skills in physicians: are the skills context specific or generalizable. BMC Med Educ. 2009; 9: 22, doi: 10.1186/1472-6920-9-22, indexed in Pubmed: 19445685.

6. Braverman G, Bereknyei Merrell S, Bruce JS, et al. Finding the Words: Medical Students' Reflections on Communication Challenges in Clinic. Fam Med. 2016; 48(10): 775-783, indexed in Pubmed: 27875600.

7. Alotaibi FS, Alsaeedi A. Attitudes of medical students toward communication skills learning in Western Saudi Arabia. Saudi Med J. 2016; 37(7): 791-795, doi: 10.15537/smj.2016.7.14331, indexed in Pubmed: 27381541.

8. Taylor $S$, Bobba $S$, Roome $S$, et al. Simulated patient and role play methodologies for communication skills training in an undergraduate medical program: Randomized, crossover trial. Educ Health (Abingdon). 2018; 31(1): 10-16, doi: 10.4103/1357-6283.239040, indexed in Pubmed: 30117467.

9. Wright KB, Bylund C, Ware J, et al. Medical Student Attitudes Toward Communication Skills Training and Knowledge of Appropriate Provider-Patient Communication: A Comparison of First-Year and Fourth-Year Medical Students. Med Educ Online. 2006; 11(1): 4594, doi: 10.3402/ meo.v11i.4594, indexed in Pubmed: 28253797.

10. Ajzen I. The theory of planned behavior. Organizational Behavior and Human Decision Processes. 1991; 50(2): 179-211, doi: 10.1016/07495978(91)90020-t.

11. Rees $C$, Sheard $C$. The relationship between medical students' attitudes towards communication skills learning and their demographic and education-related characteristics. Med Educ. 2002; 36(11): 1017-1027, doi: 10.1046/j.1365-2923.2002.01333.x, indexed in Pubmed: 12406261.

12. Cleland J, Foster K, Moffat M. Undergraduate students' attitudes to communication skills learning differ depending on year of study and gender. Med Teach. 2005; 27(3): 246-251, doi: 10.1080/01421590400029541, indexed in Pubmed: 16011948.
13. Hojat $M$, Vergare MJ, Maxwell $K$, et al. The devil is in the third year: a longitudinal study of erosion of empathy in medical school. Acad Med. 2009; 84(9): 1182-1191, doi: 10.1097/ACM.0b013e3181b17e55, indexed in Pubmed: 19707055.

14. Neumann $M$, Edelhäuser $F$, Tauschel $D$, et al. Empathy decline and its reasons: a systematic review of studies with medical students and residents. Acad Med. 2011; 86(8): 996-1009, doi: 10.1097/ ACM.0b013e318221e615, indexed in Pubmed: 21670661.

15. Tashakkori A, Creswell J. Editorial: The New Era of Mixed Methods. Journal of Mixed Methods Research. 2016; 1(1): 3-7, doi: $10.1177 / 2345678906293042$.

16. Johnson R, Onwuegbuzie A, Turner L. Toward a Definition of Mixed Methods Research. Journal of Mixed Methods Research. 2016; 1(2): 112-133, doi: 10.1177/1558689806298224.

17. Denzin NK, Lincoln YS. The SAGE Handbook of Qualitative Research. 4th ed. SAGE Publications 2011.

18. Hadi MA, Alldred DP, Closs SJ, et al. Mixed-methods research in pharmacy practice: basics and beyond (part 1). Int J Pharm Pract. 2013; 21(5): 341-345, doi: 10.1111/ijpp.12010, indexed in Pubmed: 23418918.

19. Leech $N$, Onwuegbuzie A. A typology of mixed methods research designs. Quality \& Quantity. 2007; 43(2): 265-275, doi: 10.1007/ s11135-007-9105-3.

20. Ordinance of the Minister of Science and Higher Education of May 9 , 2012 on the standards of education for faculties: medical, dentistry, pharmacy, nursing and obstetrics. [Rozporządzenie Ministra Nauki i Szkolnictwa Wyższego z dnia 9 maja 2012 r. w sprawie standardów kształcenia dla kierunków studiów: lekarskiego, lekarsko-dentystycznego, farmacji, pielęgniarstwa i położnictwa.] Retrived from: http:// prawo.sejm.gov.pl/isap.nsf/DocDetails.xsp?id=WDU20120000631.

21. Krejcie R, Morgan D. Determining Sample Size for Research Activities. Educational and Psychological Measurement. 2016; 30(3): 607-610, doi: 10.1177/001316447003000308.

22. Cleland JA. The qualitative orientation in medical education research. Korean J Med Educ. 2017; 29(2): 61-71, doi: 10.3946/kjme.2017.53, indexed in Pubmed: 28597869.

23. British Association for Educational Researchers. Ethical Guidelines for Educational Research. fourth edition, 2018. https://www.bera. ac.uk/researchers-resources/publications/ethical-guidelines-for-educational-research-2018.

24. Knowles MS. The modern practice of adult education: From pedagogy to andragogy. Chicago. Association Press 1980.

25. Knowles MS. Andragogy in action: Applying modern principles of adult learning. San Francisco. Jossey-Bass Publishers, 1984.

26. Jochemsen-van der Leeuw HG, van Dijk N, van Etten-Jamaludin FS, et al. The attributes of the clinical trainer as a role model: a systematic review. Acad Med. 2013; 88(1): 26-34, doi: 10.1097/ ACM.0b013e318276d070, indexed in Pubmed: 23165277.

27. Paice $E$, Heard $S$, Moss $F$. How important are role models in making good doctors? BMJ. 2002; 325(7366): 707-710, doi: 10.1136/ bmj.325.7366.707, indexed in Pubmed: 12351368. 
28. Egnew TR, Wilson HJ. Faculty and medical students' perceptions of teaching and learning about the doctor-patient relationship. Patient Educ Couns. 2010; 79(2): 199-206, doi: 10.1016/j.pec.2009.08.012, indexed in Pubmed: 19748201.

29. Junod Perron N, Sommer J, Louis-Simonet M, et al. Teaching communication skills: beyond wishful thinking. Swiss Med Wkly. 2015; 145: w14064, doi: 10.4414/smw.2015.14064, indexed in Pubmed: 25664624.

30. Rees $C E$, Sheard CE, McPherson AC. A qualitative study to explore undergraduate medical students' attitudes towards communication skills learning. Med Teach. 2002; 24(3): 289-293, doi: 10.1080/01421590220134123, indexed in Pubmed: 12098416.

31. Nogueira-Martins MC, Nogueira-Martins LA, Turato ER. Medical students' perceptions of their learning about the doctor-patient relationship: a qualitative study. Med Educ. 2006; 40(4): 322-328, doi: 10.1111/j.13652929.2006.02411.x, indexed in Pubmed: 16573667.

32. Rees C, Sheard C, McPherson A. Medical students' views and experiences of methods of teaching and learning communication skills. Patient Educ Couns. 2004; 54(1): 119-121, doi: 10.1016/\$07383991(03)00196-4, indexed in Pubmed: 15210269.

33. Adamczuk J, Nieckula M, Dabrowska A, et al. Recommendations for the use of simulation methods in a selected area of health sciences based on an example simulation scenario. Disaster and Emergency Medicine Journal. 2019; 4(4): 173-179, doi: 10.5603/demj.a2019.0031.

34. Abelsson A. Learning through simulation. Disaster and Emergency Medicine Journal. 2017; 2(3): 125-128, doi: 10.5603/demj.2017.0027.
35. Williams KN, Ramani S, Fraser B, et al. Improving bedside teaching: findings from a focus group study of learners. Acad Med. 2008; 83(3): 257-264, doi: 10.1097/ACM.0b013e3181637f3e, indexed in Pubmed: 18316871.

36. Tariq M, Motiwala A, Ali SU, et al. The learners' perspective on internal medicine ward rounds: a cross-sectional study. BMC Med Educ. 2010; 10: 53, doi: 10.1186/1472-6920-10-53, indexed in Pubmed: 20618929.

37. Berkhof M, van Rijssen HJ, Schellart AJM, et al. Effective training strategies for teaching communication skills to physicians: an overview of systematic reviews. Patient Educ Couns. 2011; 84(2): 152-162, doi: 10.1016/j.pec.2010.06.010, indexed in Pubmed: 20673620.

38. Veloski J, Boex JR, Grasberger MJ, et al. Systematic review of the literature on assessment, feedback and physicians' clinical performance: BEME Guide No. 7. Med Teach. 2006; 28(2): 117-128, doi: 10.1080/01421590600622665, indexed in Pubmed: 16707292.

39. Malhotra A, Gregory I, Darvill E, et al. Mind the gap: Learners' perspectives on what they learn in communication compared to how they and others behave in the real world. Patient Educ Couns. 2009; 76(3): 385-390, doi: 10.1016/j.pec.2009.07.024, indexed in Pubmed: 19674863.

40. Rosenbaum ME, Axelson R. Curricular disconnects in learning communication skills: what and how students learn about communication during clinical clerkships. Patient Educ Couns. 2013; 91(1): 85-90, doi: 10.1016/j.pec.2012.10.011, indexed in Pubmed: 23154147. 